\title{
SERIAL TELEVISI DEXTER SEBAGAI ANAKRONISME DALAM SASTRA POPULER
}

\author{
Ida Rochani Adi \\ FIB Universitas Gadjah Mada \\ email: idaadi@ugm.ac.id
}

\begin{abstract}
Abstrak
Penelitian dalam konteks sastra populer ini memaparkan dua hal, yaitu (1) bagaimana formula penokohan Dexter dalam serial televisi Dexter menyalahi tradisi penokohan sastra, dan (2) bagaimana formula nilai moral didramatisasikan melalui tokoh Dexter yang dikategorikan sebagai sosiopat, psikopat, pembunuh berseri, dan tidak bermoral. Objek penelitian adalah serial televisi Dexter yang menduduki tingkat kepopuleran kelima di dunia. Data dikumpulkan dengan teknik studi dokumentasi terhadap 84 episode serial televisi Dexter yang ditayangkan sejak tahun 2006. Data dianalisis dengan teknik analisis konten dan deskriptif kualitatif. Berdasarkan hasil penelitian dan pembahasan diperoleh kesimpulan sebagai berikut. Pertama, terdapat penyimpangan atau anakronisme penokohan melalui tokoh utama serial ini. Kedua, pola nilai moral yang didramatisasikan ini ternyata masih membawa nilai konvensional meskipun dalam bentuk yang berbeda.
\end{abstract}

Kata kunci: sastra populer, penokohan, anakronisme, nilai moral

\section{THE DEXTER TELEVISION SERIAL AS AN ANACHRONISM IN POPULAR LITERATURE}

\begin{abstract}
In the popular literature context, this study aims to investigate: (1) how the formulation of the characterization of Dexter in the television serial Dexter violates the tradition of literary characterization, and (2) how the formula of moral values is dramatized through Dexter, who is a sociopath, psychopath, serial killer, and person without moral. The research object was the television serial Dexter, which ranks five in popularity in the world. The data were collected by documenting 84 episodes of the serial having been broadcast since 2006. They were analyzed by means of content analysis and qualitative descriptive techniques. Based on the findings, the conclusions are as follows. First, there is a violation or anachronism of characterization through the main character in the serial. Second, the dramatized moral values still contain conventional values although they are in different forms.
\end{abstract}

Keywords: popular literature, anachronism, moral values

\section{PENDAHULUAN}

Sejalan dengan perkembangan teknologi, kehidupan manusia dengan budaya yang secara dramatis ditransformasikan oleh interaksi global mengakibatkan pe- rubahan tidak hanya dalam cara manusia berpikir dan merasakan tetapi juga dalam mengkonstruksi nilai-nilai moral. Hal ini terlihat dalam kemunculan protagonis yang menyalahi konvensi tokoh, protagonis atau hero yang ada melalui serial tele- 
visi berjudul Dexter. Serial ini ditayangkan pertama kali di tahun 2006 dan sampai dengan tahun 2012, 84 seri telah ditayangkan. Cerita dari serial ini berkisar dalam kehidupan seorang ahli forensik dalam menganalisis pola noda darah atau yang disebut dengan blood spatter pattern analyst. Dengan keahlian tersebut Dexter bekerja membantu kepolisian Miami. Yang menarik dalam serial ini adalah bahwa Dexter selain bekerja di kepolisian, dia adalah seorang pembunuh berantai yang telah membunuh lebih dari seratus orang dalam kurun waktu 20 tahun.

Sampai dengan tahun 2012, serial televisi Amerika ini terdiri atas 7 season yang setiap season-nya terdiri atas 12 seri yang masing-masing mempunyai judul sendiri-sendiri. Serial TV Dexter berangkat dari novel yang ditulis oleh Jeff Lindsay Darkly Dreaming Dexter. Akan tetapi, novel tersebut hanya diadaptasi dalam season pertama saja karena dalam season-season berikutnya, cerita Dexter mengalir sendiri dan tidak berdasar pada novel tersebut.

Meskipun tokoh ini adalah pembunuh berantai, dia merupakan tokoh pujaan jutaan orang di dunia. Hal ini dapat dilihat dari kepopuleran serial ini yang mencapai lebih dari tiga juta penonton (Kondology, 2013), dan jumlah tersebut belum termasuk penonton Indonesia yang menonton melalui saluran TV kabel atau yang menonton dengan membeli DVD bajakan. Berbagai komentar di berbagai media sosialmenunjukkan pemujaan terhadap pembunuhberantaiini.Good (2010) dalam blognya, misalnya, mengemukakan: "of course we love him, that darling murderer". Pernyataan-pernyataan serupa dapat ditemukan diberbagai blog-blog pribadi lain, komentar, dan artikel-artikel di internet. Menurut Reisch (2011:xiv): "Dexter represents a way of life and can be seen as a superhero". Muir (2011: 13) juga menegaskan hal yang sama: "Perhaps Dexter is indeed the Superman for our day and age: an outsider to humanity who can comment objectively upon it, and act in its best interest... In his unique way, Dexter is a champion for truth and justice-even if his clinical approach to punishing evil is not precisely the American way".

Memang benar bahwa sastra populer sering dianggap sebagai sajian yang menyesatkan kehidupan manusia, terutama anak muda, terlebih lagi kekerasan yang disajikan oleh televisi yang menurut penelitian terhadap 707 penonton, menonton televisi akan berdampak pada peningkatan perilaku yang agresif yang nantinya berdampak pada perilaku kekerasan (Johnson, et al, 2002). Dengan kata lain, sastra populer, dalam hal ini Dexter yang menyajikan kekerasan, akan berdampak pada kekerasan. Apabila demikian, akankah sastra populer dapat dianggap sebagai karya sastra?

Sastra Inggris atau sastra Amerika yang dipelajari pada umumnya dianggap sebagai sarana dalam pengembangan empat kompetensi berbahasa, yaitu menyimak, berbicara, membaca, dan menulis. Karena itulah mengajar sastra Amerika dilakukan di kelas bahasa Inggris atau dengan kata lain, dalam banyak kasus kelas bahasa Inggris adalah kelas sastra Inggris. Dalam mata kuliah di program studi Sastra Inggris tersebut, teks-teks sastra yang berbahasa Inggris dipakai untuk mengembangkan kemampuan mahasiswa berbahasa Inggris. Akan tetapi, dalam praktiknya, mempelajari sastra Inggris di perguruan tinggi diletakkan pada konteks humaniora secara luas. Hal ini berarti, tidak hanya ketrampilan berbahasa saja yang dilatih, tetapi juga mempelajari filsafat dan nilai moral yang melekat dalam mempelajari sejarah sastra, latar belakang penulis, kritik sastra, estetika sastra dan rangkaian pemikiran yang dibawa oleh karya sastra. Dengan demikian, sastra menyajikan jalan atau cara tidak hanya bagaimana mengembangkan keterampilan dan cara berpikir kritis saja tetapi juga mengembangkan nilai dan kemampuan menilai moral. Karena selalu terlibat da- 
lam refleksi yang kritis dan dalam tentang kehidupan manusia, mahasiswa diharapkan dapat memperbaiki karakternya. Inilah yang menjadi sebab adanya anggapan bahwa ilmu sastra dan filsafat merupakan garda depan pendidikan karakter dan pelestarian budaya.

Nilai-nilai moral manusia atau masyarakat yang dikandung dalam karya sastra menjadi penting sehingga tidak mengherankan terdapat pendapat yang mengatakan bahwa "Betapapun menariknya sebuah karya kalau ia berisi pengalaman yang menyesatkan hidup manusia, ia tidak pantas disebut sebagai karya sastra" (Sumarjo, 1984:14). Jadi, karya sastra harus berisi ajaran yang membawa manusia kepada nilai yang baik. Pendapat ini tidaklah berarti dalam konteks Indonesia saja. Hoggart (1973:11), seorang ahli sastra, filsafat dan cultural studies berpendapat sama: "I value literature because of the way - the peculiar way - in which it explores, re-creates and seeks for the meanings in human experience; ...". Akan tetapi, yang dimaksudkan dengan "tidak menyesatkan hidup manusia" dan "meaning" dapat saja berbeda karena standar nilai yang berbeda dalam masing-masing budaya. Meskipun demikian, terdapat nilai universal yang dapat diterima oleh semua masyarakat seperti dapat dibaca pada kutipan berikut ini.

... that meanings, and values, discoverd in particular societies and by particular individuals, and kept alive by social inheritance and by embodiment in particular kind of work, have proved to be universal in the sense that when they are learned, in any particular situation, they can contribute radically to the growth of man's powers to enrich his life, to regulate his society, and to control his environment. ... it can only become active within particular societies, being shaped, as it does so, by more local and temporary systems (William, 1998: 49).
Dari fenomena yang disebutkan di atas, pertanyaan yang mucul kemudian adalah bagaimana seorang pembunuh berantai yang mengoleksi darah korbannya dapat menjadi hero dan dipuja oleh banyak penonton televisi dalam tujuh tahun terakhir ini? Kalau karya sastra dituntut untuk membawa nilai moral dan pembawa nilai adalah protagonis cerita tersebut, pertanyaan yang muncul berikutnya adalah nilai moral seperti apakah yang dibawa oleh seorang protagonis yang melakukan pembunuhan berantai. Apakah nilai moral yang dibawanya masih mengikuti nilai moral sebelumnya ataukah ada perubahan konsep nilai. Pertanyaan-pertanyaan tersebutlah yang menjadi pertanyaan yang akan dijawab penelitian ini.

Nilai moral dan nilai kehidupan pada dasarnya berubah sejalan dengan cara orang menghadapi kenyataan hidup yang selalu berubah. Perubahan ini tentunya berdampak pada selera masyarakat karena selera berjalan sesuai dengan keinginan dan kebutuhan masyarakat. Jadi, perubahan selera adalah refleksi dari sikap dan perilaku masyarakat. Dalam kaitan ini, dampak televisi terhadap perilaku masyarakat, terutama kaum muda, sering dibahas. Penelitian tentang efek kekerasan yang ditayangkan televisi atau media lain banyak dilakukan orang. Akan tetapi "Dexter" merupakan fenomena baru dalam ranah sastra populer yang, dengan demikian, penting untuk diteliti.

Dari sepuluh rating televisi tertinggi, tercatat di antaranya adalah serial-serial televisi antara lain Game of Thrones, Breaking Bad, The Wire, The Sopranos, and Dexter (IMDb, 2013). Serial-serial televisi tersebut bercerita tentang kekerasan, kriminalitas, pembunuhan, kerakusan akan kekuasaan, dealer narkoba, peperangan mutilasi, pembunuhan, kehidupan mafia, pembunuh berantai, dlsb. Kenyataan bahwa separuh dari rating tertinggi serial televisi adalah cerita-cerita tentang kekerasan menun- 
jukkan bahwa sekarang ini banyak orang menyukai cerita-cerita tentang kekerasan dan kriminalitas. Hal ini merupakan tantangan bagi dosen dan siapa saja yang menyuntuki bidang dengan kesastraan, filsafat, dan masalah-masalah moral. Jadi, penelitian ini bertujuan: (1) memberi gambaran tentang anakronisme tokoh dan penokohan dalam serial televisi "Dexter" yang merupakan refleksi yang ada dalam masyarakat (2) menjelaskan anakronisme nilai-nilai, perspektif, cara pandang dunia, dan kepercayaan yang dipikirkan dan dimiliki oleh tokoh.

Istilah anakronisme berarti ketidak konsistenan dalam karya sastra, atau "an error in chronology or timeline in a piece of art or literature" (Scholasticus, 2012). Argumentasi yang dapat dibangun di sini adalah bahwa anakronisme ini dapat terjadi sejalan dengan perubahan selera masyarakat karena terdapat banyak anakronisme yang tercatat sepanjang sejarah sastra di dunia. Hal ini terjadi karena adanya kecenderungan bahwa penulis atau pembuat fiksi menciptakan inovasi dalam karyanya dalam rangka membangun originalitas atau mencari peluang keluar dari kejenuhan konvensi yang ada. Menurut Jinks (1974:118) “a departure from the conventional and ordinary uses of words, enables the writer to coin a fresh or unique expression or perhaps even startle his reader into considering a subject in a new or unusual light".

Menyalahi konvensi yang ada dalam fiksi akan pula berdampak pada nilai yang ada dalam karya tersebut karena nilai yang dipahami dan dipercaya oleh pembuat film atau fiksi tersebutlah yang mewarnai karyanya seperti pendapat Williams (1998:49) berikut ini.

... the dramatic form, ... not only have an artistic tradition behind them, the work of many men, but can be seen to have been shaped, not only by the demands of the experience, but by the particular social forms through which the dramatic tradi- tion developed. ... the dramatic forms gave meaning only in the contexts to which we have assigned them.... The dramatic form passes beyond its context, and becomes an element in a major and general dramatic tradition, in quite different societies."

Nilai yang termuat dalam suatu karya akan dapat tersampaikan kepada masyarakat dan akan dapat terjadi apabila masyarakat mengetahui nilai tersebut. Hal ini sesuai dengan pendapat bahwa "the real potentialities and limitations of literature as an expression of socio-political commitment can be achieved only if the writer and reader alike understand what writing is" (Caute, 1972: 145). Artinya, apabila penulis dan pembaca suatu karya memahami nilai yang ada dalam suatu karya, maka sastra populer, termasuk film populer mempunyai nilai yang dipahami dan dipercaya kebenarannya oleh kedua belah pihak tersebut. Dengan demikian, Dexter yang merupakan tokoh, karakter, protagonis, atau hero yang juga pembunuh berantai tentunya mempunyai nilai yang dipahami dan dipercaya dapat menjadi pedoman hidup seseorang karena melalui protagonislah penulis atau pencipta fiksi menyampaikan nilai-nilai moral tersebut.

\section{METODE}

Sumber data penelitian adalah 84 seri film yang merupakan serial televisi dari tujuh season berjudul Dexter, yang ditayangkan tahun 2006-2012. Untuk kepentingan penelitian ini dilakukan pendokumentasian, studi pustaka dan analisis isi.

Teknik pengumpulan data dilakukan dengan teknik studi dokumentasi terhadap 84 seri film Dexter sebagai data primer dan dokumentasi terhadap sejumlah buku-buku, artikel, atau informasi lain terkait dengan fokus penelitian sebagai data sekunder. Teknik analisis data yang dipakai dengan analisis konten dan inferensial. Analisis konten dilakukan 
dalam menganalisis isi dilakukan dengan pendekatan semantis dalam rangka meneliti keterhubungan antarfilm serial televisi tersebut sehingga diperoleh gambaran, "the genre building blocks" (Altman, 1986: 30), yang menyeluruh dan utuh atas bentuk-bentuk nilai dan perubahan yang dibawa dalam film-film tersebut. Validitas dan reliabilitas data dicapai dengan validitas semantis dan validitas intra-rater.

\section{HASIL DAN PEMBAHASAN}

Sesuai dengan tujuan penelitian, pada bagian ini disajikan hasil dan pembahasan penelitian yang mencakup dua hal, yaitu: (1) anakronisme protagonis dalam serial televisi "Dexter" yang merupakan refleksi masyarakat (2) anakronisme nilai-nilai, perspektif, cara pandang dunia, dan kepercayaan tentang moral yang dipikirkan dan dipercaya oleh tokoh cerita.

\section{Anakronisme Protagonis}

Protagonis atau hero tidaklah dapat lepas dari fiksi karena melalui protagonis cerita, dramatisasi dalam kehidupan dapat diciptakan. Nilai yang dibawa oleh protagonis dapat berubah, tetapi eksistensinya cenderung tetap. Hal ini sesuai dengan yang diargumentasikan oleh Linberg berikut ini.

Through the ages men have always needed and found heroes to embody their aspirations, to compensate for their failures, to inspire them to explore new paths of mankind. I think we still need and will continue to find them.... We should admit, however, that our concept of a hero has changed. The Homeric hero is outdated. The Biblical hero of the David and Goliath Story, beautiful as it is, is hard to imagine today (Linberg, 1979:309).

Konvensi yang ada selama ini, tokoh sebagai pembawa nilai moral, hidup dengan aturan-aturan yang membawanya berperilaku seperti nilai-nilai moral yang diyakininya. Biasanya, protagonis cerita- cerita populer bergenre action, crime, detektif, petualangan, atau cerita-cerita yang mengeksplorasi maskulinitas, adalah seorang yang pemberani, pandai, terampil, dan mendedikasikan hidupnya untuk masyarakat. Tokoh Dexter sebenarnya memenuhi semua kriteria tersebut, akan tetapi kesenangannya membunuh yang kemudian menjadi pembunuh berantai inilah yang membuat "Dexter" menunjukkan adanya anakronisme dalam penokohan.

Adi (2008:173-182) dalam penelitiannya tentang cerita-cerita petualangan Amerika mencatat bahwa seorang hero mempunyai ciri-ciri beberapa hal, yaitu: (1) tidak ada sifat pengecut dan licik dalam dirinya, (2) mempunyai sifat pemberani, (3) mempunyai motif kemanusiaan yang kuat, (4) pembunuhan dilakukan karena mempertahankan diri, (5) penyendiri, (5) tidak dinamis dan pendiam meskipun sensitif, (6) mempunyai integritas tinggi, dan (7) dapat mengendalikan kemampuan, pikiran, dan perasaannya. Kriteria protagonis tersebut dapat juga dikatakan sebagai mainstream cerita populer Amerika yang mendramatisasikan tokoh maskulin seperti halnya "Dexter".

Berdasarkan kriteria tersebut terdapat dua hal yang membuat penokohan Dexter berubah dari mainstream, yaitu: (1) bahwa Dexter adalah seorang pembunuh berantai yang tindakannya bukan karena mempertahankan diri. (2) Dexter bukanlah orang yang dapat mengendalikan kemampuan, pikiran dan perasaannya, meskipun dapat mengendalikannya dalam kasus-kasus tertentu. Dengan perubahan tersebut, pertanyaan yang muncul kemudian adalah apakah sang protagonis ini menjadi seorang yang mempunyai ciri sebagai antagonis cerita? Menurut Adi (2008: 170), sifat-sifat antagonis dalam genregenre kriminal dan petualangan dapat digolongkan dalam lima kategori, yaitu: (1) orang yang mencari kekuasaan dan kekayaan, (2) orang yang mengganggu 
ketentraman masyarakat, (3) teroris yang memaksakan ideologinya, (4) pembalasan dendam, dan (5) orang yang kecewa terhadap kenyataan dan terdorong mengubah nilai masyarakat. Jadi, meskipun pada kenyataannya Dexter melakukan pembunuhan berantai, dia tidaklah mempunyai kriteria sebagai seorang antagonis.

Anakronisme penokohan yang terlihat adalah diciptakannya Dexter sebagai seorang pembunuh berantai. Pembunuhan berantai seperti ini pada umumnya dilakukan oleh antagonis dan melakukannya karena gangguan mental. Dalam "Dexter" formula tersebut berubah, pembunuhan yang dilakukan karena gangguan mental tidak dilakukan oleh antagonis, tetapi oleh protagonis. Sebagai protagonis Dexterpun dapat dikatakan mempunyai gangguan mental. Hal ini dapat dilihat dalam monolog berikut:

"I just know there's something dark in me and I hide it. I certainly don't talk about it, but it's there always, this Dark Passaanger. And when he's driving, I feel alive, half sick with the thrill of complete wrongness. I don't fight him. I don't want to He's all I've got. Nothing else could love me, not even ... especially not me. Or is that just a lie the Dark Passenger tells me?" ("Dexter" Season 2, Episode 3)

Dari kutipan di atas, Dexter menyebut tokoh Dark Passenger yang menurutnya menjadi "milik satu-satunya". Sebenarnya tokoh ini adalah bisikan yang selalu hadir dalam pikiriannya dan yang mendorongnya untuk membunuh. Kehadiran bisikan, yang selalu mewarnai setiap serinya, menunjukkan bahwa Dexter menderita gangguan mental. Selain itu, sama dengan pembunuh psikopat dalam cerita-cerita pembunuh berantai lain yang mengoleksi bagian tubuh korban, Dexter juga melakukan tindakan tersebut. Dia mengoleksi tetesan darah korban dengan cara menyayat pipi korban dan menyimpan darah tersebut di laci. Dexter, seperti pembunuh berantai dalam cerita-cerita bergenre kriminal lain, tidak merasa takut terhadap apa yang telah dia lakukan. Hal ini terlihat misalnya pada peristiwa ketika adik tirinya menemukan slide-slide dengan darah korban dilacinya:

Deb: Did you kill all these people?(

Dexter: I did.(

Deb: Are you a serial killer?(

Dexter: Yes. ("Dexter", Season 7 Episode 8)

Dexter membunuh orang, melanggar hokum, dan mengoleksi darah korbannya tetapi ironisnya, dia bahkan sangat terganggu dengan kekerasan orang "Needless to say I have some unusual habits, yet all these socially acceptable people can't wait to pick up hammers and publicly smash their food to bits. Normal people are so hostile" ("Dexter", Season 1 Episode 1). Padahal, seperti yang terlihat dalam kutipan di atas, apa yang dilakukan orang lain tersebut tidaklah seberat apa yang dilakukannya. Dalam episode yang lain dia bahkan merasa bahwa apa yang dilakukannya bukanlah hal yang seharusnya tidak dilakukan dalam masyarakat yang menganut hukum. Menurut Dexter: "I' $m$ the helpful handyman, how evil could I be?" ("Dexter", Season 1 Episode 11). Bahkan, melakukan pembunuhan dianggap sebagai suatu kelakar seperti yang terlihat dalam perkataannya yang berkenaan dengan ayah dan ibu tiri yang telah membesarkannya: "Harry dan Dorris Morgan did a wonderful job raising me. But they're both dead now. I didn't kill them, honest" ("Dexter", Season 1, Episode 1)

Konvensi lain dalam cerita-cerita tentang tokoh yang mempunyai gangguan mental sehingga menjadi pembunuh berantai adalah bahwa dia tidak mempunyai emosi, seperti tidak mempunyai rasa sedih, cinta, penyesalan, harga diri, jiijk, malu, dan rasa setia kawan karena dia selalu penyendiri. Semua sifat tersebut dipunyai Dexter kecuali rasa cinta terhadap Debra, adik tirinya dan rasa senang terhadap anak-anak. Karena itulah dia 
diajar ayah angkatnya, yang mengetahui kebutuhannya membunuh, untuk bersikap seperti manusia biasa yang bersosialisasi dengan orang lain. Dia kemudian berpura-pura menjadi orang normal.

Dalam rangka menjadi seorang hero cerita populer yang mempunyai kemampuan lebih dari orang biasa, Dexter selayaknyalah harus diartikulasikan dalam keadaan yang dapat memenuhi standar masyarakat sehingga masyarakat dapat menerimanya. Oleh karena itu, meskipun terjadi anakronisme, penokohan pada Dexter seharusnyalah dapat dipahami, diterima, dan dimaklumi oleh masyarakat meskipun dia adalah seorang pembunuh. Untuk memenuhi selera masyarakat, terdapat tiga faktor penting yang dibangun, yaitu: (1) membuka celah kemanusiaan, (2) memberikan faktor thriller, dan (3) mengakomodasi intelektualitas manusia.

Dexter menunjukkan sisi kemanusiaannya dengan kemampuannya memilih korban. Semua korban yang dibunuhnya adalah pembunuh. Dia tidak pernah membunuh orang yang tidak bersalah, kecuali dalam season 4, dia membuat kesalahan ketika dia membunuh seorang fotografer yang sebenarnya tidak bersalah. Selain hanya membunuh pembunuh yang dapat diartikan membela kepentingan masyarakat, dia mengetahui bahwa dia mempunyai kelainan kejiwaan. Hal tersebut dapat dilihat, misalnya, dari pernyataannya: "I remember when my life was easy, when the only question I worried about was, who's next?" Now it's "how can I dodge my protective detail?" and "what should I do with my hostage? These are not easy questions. Murder is not enjoyment" ("Dexter", Season 2, Episode 10). Atau dalam percakapan berikut:

Miguel: They deserved it. I'm not like them.

Dexter: You are. Admit it.

Miguel: 'I'm like you'.

Dexter: 'No. No, no, no, no. I know I'm a monster'. ("Dexter" Season 3, Episode 11)
Pembuat serial TV “Dexter" dalam usahanya memberikan rasionalisasi penokohan psikopat ini melakukannya dengan menempatkan Dexter sebagai objek dari kekuatan yang tidak diinginkannya. Kondisi inilah yang tampaknya dapat membuat penonton memaklumi apa yang dilakukannya, seperti yang terlihat dalam komentar berikut: "Our empathy for Dexter goes deeper than merely hoping he does not get caught. As Dexter grapples with life, we witness his struggle and sympathize. We can see ourselves in Dexter: his feeling of alienation, his wry take on the people around him and then incomprehensible behavior" (Waller, 2010:105)

Dalam hal menarik penonton, penampilan Dexter terlihat seperti halnya manusia normal, sopan, dan baik hati, seperti yang terlihat dalam kutipan berikut.

Dexter: 'I can kill a man, dismember his body, and be home in time for Letterman. 'But knowing what to say when my girlfriend's feeling insequre. ... I'm totally lost' ("Dexter", Season1 Episode 2)

atau

Arthur: 'You think you're better than I am?' Dexter: 'No. But I want to be' ("Dexter", Season 4, Episode 12)

Sisi-sisi kemanusiaan yang menempatkan keluarga, teman, dan anak-anak merupakan formula konvensional sastra Amerika, baik sastra populer maupun sastra adiluhung. Pembicaraan Dexter berikut ini juga menunjukkan hal itu.

Deb: 'You don't like Quinn much'

Dexter: 'I don't like him but I wan't you to be happy' ("Dexter", Season 5, Episode 12)

Juga ketika adiknya bertanya kemana dia akan pergi, Dexter menjawab: "Kill a guy you're looking for. Save a kid. Remember to pick up diapers" ("Dexter", Season 4, Episode 10). Selain itu, Dexter juga seorang yang mempunyai aktivitas seperti halnya manusia normal lainnya seperti 
mempunyai pekerjaan, pacar, dan dapat berkomunikasi dengan baik meskipun pendiam.

Hal lain tampak dalam pernyataanpernyataannya yang dapat mengundang empati penontonnya, misalnya ketika dia sedang membunuh dia berpikir, yang pikirannya diketahui oleh penonton melalui voice over, bahwa perbuatannya tersebut akan berdampak pada kehidupan orang lain yang tidak bersalah. Pikiran-pikiran yang menyalahkan diri sendiri inilah yang membuat Dexter dapat "termaafkan" dan mendapat empati penonton. Penonton 'dipaksa' untuk memaklumi pembunuhan berantainya dan seolah meminta penonton untuk mengasihani dia, seperti terlihat dalam kutipan berikut: "I love Halloween. The one time of year when everyone wears a mask... not just me. People think it's fun to pretend you're a monster. Me, I spend my life pretending I'm not." ("Dexter", Season 1 Episode 4)

Dalam hal penciptaan "Dexter", aspek thriller terhadap penonton terlihat menjadi faktor utama film serial ini. Cara membuat penonton tegang dan berharap cemas atas hal yang akan terjadi bukanlah hal yang mudah. Kriminalitas dan kekerasan bersama-sama menciptakan ketegangan tersebut. Meskipun demikian, kriminalitas dan kekerasan tersebut tidak menjamin popularitasnya. Jadi dapat ditarik kesimpulan bahwa bagaimana membuat kriminalitas dan kekerasan tersebut divisualisasikanlah menjadi faktor utamanya.

Dramatisasi kebaikan melawan kejahatan dalam film-film Amerika selalu diakhiri dengan kematian tokoh jahat dengan cara yang mengenaskan sehingga muncul konvensi formula "bad guy dies twice". Hal ini menunjukkan pentingnya eksploitasi perasaan penonton. Penonton diajak memaklumi dan mengakomodasi tindakan brutal hero dalam membasmi kejahatan tersebut (Adi, 2011: 169). Fenomena pembunuh berantai sebagai hero, yang dapat dikatakan menyalahi konvensi tersebut di atas, dapat menunjukkan adanya peningkatan skala kepuasan penonton dalam melihat hukuman terhadap kejahatan sehingga dapat menerima invensi tersebut. Menurut Slosser (2002:13):

"The superheroes, like frontier cowboys before then, symbolize 'the embodiment of American myth of the lone, rugged individual who comes into society and cleans it up. We all want to do it, but we don't know how to do it. We live our everyday lives that don't allow for this kind of simplistic vision. Se we cheer for it".

Kutipan tersebut menunjukkan konvesi superhero dalam mitos Amerika merupakan pandangan yang terlalu sederhana bagi masyarakat sekarang. Dengan kata lain, penonton sekarang menginginkan tontonan yang lebih menantang. Hal inilah yang menjawab mengapa seorang pembunuh berantai, seperti Dexter, dapat menjadi protagonis yang dapat diterima oleh masyarakat. Michaud (2011:38) mengatakan bahwa karena Dexter tidak dapat berbuat lain selain membunuh, dia tidak dapat disalahkan atas perbuatannya. Kalau tanggung jawab moral dipertanyakan, memang benar Dexter melakukan kesalahan, tetapi kalau dilihat bahwa Dexter tidak mempunyai pilihan antara membunuh dan tidak membunuh, maka dia tidak dapat disalahkan.

Argumentasi tentang berkembangnya tingkat kepuasan penonton di atas itu pulalah yang dapat dijadikan pijakan untuk argumentasi berikutnya yaitu bahwa faktor yang berhubungan dengan intelektualitas manusia menjadi faktor penting dalam membuat penonton menerima Dexter sebagai superhero, meskipun dia seorang pembunuh berantai. Munculnya fenomena peningkatan cerita bergenre detektif, horor, criminal, thriller, dan fantasi yang semakin rumit di televisi menunjukkan bahwa masyarakat sekarang makin 
membutuhkan tontonan yang menantang dan makin membutuhkan kecerdasan dalam memahami apa yang ditontonnya. Hal ini juga dapat menjawab mengapa "Dexter" begitu dipuja masyarakat dan sekaligus juga menjawab mengapa terjadi anakronisme melalui penciptaan "Dexter" seperti yang dikatakan oleh Sherman (2009) berikut ini.

Crime drama has gotten a lot more sophisticated. There's greater tolerance for anti-heroes like Tony, Swearengen, and Avon these days. Maybe it's just because we take in so much of it, you have to keep adding plot twists to keep it interesting. Or maybe it's because we're better at admitting there's a natural tension between abiding by, and defying the lawe( ( Or maybe it's because the tension is growing (Sherman, 2009)

\section{Anakronisme Nilai-Nilai Moral}

Sesuai dengan tujuan penelitian, bagian ini adalah hasil analisis tentang nilai moral yang dikandung cerita "Dexter", yang secara umum dikatakan sebagai cerita yang tidak bermoral karena hero atau protagonisnya adalah seorang pembunuh berantai. Bahwa hero menegakkan hukumnya sendiri baik secara legal maupun illegal bukanlah hal baru dalam tradisi sastra atau legenda Amerika maupun Inggris sekalipun, misalnya cerita tentang
Robin Hood, Jango, atau Batman. Tokohtokoh seperti ini dikenal dengan sebutan vigilante. Tokoh vigilante ini biasanya hadir karena ketidakmampuan aparat pemerintah dalam menegakkan keadilan atau ketidakadilan pihak yang berkuasa.

Di Amerika, kriminalitas yang dikategorikan sebagai tindakan kekerasan atau kejahatan adalah "Murder and nonnegligent man slaughter is based on police investigations, as opposed to the determination of a medical examiner or judicial body, includes willful criminal homicides, and excludes attempts and assaults to kill, suicides, accidental deaths, justifiable homicides, deaths caused by negligence" 2 Jadi main hakim sendiri dengan alasan apapun dikategorikan sebagai suatu kejahatan. Oleh karena itu, Dexter dapat dikategorikan sebagai seseorang yang melanggar hukum dan melakukan tindakan kriminal. Meskipun Dexter adalah seorang vigilante, dia tidak dapat dikategorikan seperti tokoh protagonis konvensional.

Film serial TV seperti "Dexter" adalah produk manusia yang dengan sendirinya terikat pada nilai yang berlaku sesuai dengan pengalaman manusia. Kenyataan bahwa "Dexter" popular, tentunya berasal dari nilai-nilai moral dan perilaku yang dipahami dan diterima oleh masyarakat. Pertanyaan yang muncul kemudian adalah nilai-nilai moral seperti apakah yang

Tabel 1. Serial Televisi Terpopuler 2012-2013

\begin{tabular}{ccll}
\hline Peringkat & Tahun Mulai Tayang & \multicolumn{1}{c}{ Judul } & \multicolumn{1}{c}{ Genre } \\
\hline 1. & 2011 & "Game of Thrones" & Fantasi petualangan \\
2. & 2013 & "Under the Dome" & Horor Scifi \\
3. & 2010 & "Walking Dead" & Horor Thriller \\
4. & 2008 & "Breaking Bad" & Crime thriller \\
5. & 2006 & "Dexter" & Crime thriller \\
6. & 2008 & "True Blood" & Fantasi thriller \\
7. & 2010 & "Pretty Little Liars" & Misteri thriller \\
8. & 2007 & "The Big Bang Theory" & Komedi \\
9. & 2011 & "Teen Wolf" & Horor thriller \\
10. & 2010 & "Supernatural" & Fantasi thriller \\
\hline
\end{tabular}

Sumber: IMDb (2013) 
dibawa oleh protagonis ini sehingga penonton dapat menerima kejahatan atau kekerasan Dexter?

Data base film televisi IMDb mencatat, sekarang ini sembilan dari sepuluh peringkat tertinggi serial televisi terpopuler, yang dilihat tidak hanya dari rating atau jumlah penonton, adalah bergenre misteri, kriminal, thriller dan fantasi, seperti yang terlihat dalam Tabel 1.

Data Tabel 1 menunjukkan bahwa "Dexter" muncul di antara serial-serial yang menyajikan kekerasan, meskipun hanya "Dexter"lah yang mempunyai protagonis lebih keras daripada yang lain. Sehubungan dengan fenomena "Dexter" ini, Reish berpendapat: "Perhaps the greatest sifnificance of Dexter is the suggestion that the entire history of philosophy has been ignoring something very, very important" (Reisch, 2011: xiv). Dari pendapat Reisch ini dapat ditarik kesimpulan bahwa terdapat nilai moral yang mendasari penciptaan tokoh utama Dexter yang berbeda dengan konvensi nilai yang selama ini mendasari penciptaan fiksi yang ada. Untuk memberi pemaknaan nilai moral yang dibawa Dexter, terlebih dulu dilihat nilai moral apakah yang diyakini oleh tokoh ini.

Dexter adalah seorang yatim piatu yang dibesarkan oleh seorang polisi Harry Morgan. Ketika berumur tiga tahun dia melihat ibunya dibunuh dengan kejam dan pengalaman inilah yang membuatnya dia menjadi pembunuh ketika dewasa. Keinginan untuk membunuh ini diketahui oleh ayah angkatnya dan dia memberi Dexter aturan main sebagai pembunuh, yaitu: (1) Dexter tidak boleh tertangkap; (2) korban Dexter harus seorang pembunuh yang membunuh tanpa alasan, dan kalau dibiarkan akan membunuh lagi dan; (3) Dexter harus memastikan bahwa korbannya memang bersalah. Aturan inilah yang kemudian diterapkan dalam menjalani kehidupannya sebagai pembunuh berantai, seperti yang dikatakannya berikut ini.
That's why he gave me a code. It cost him his life, but it kept me alive through incredible trials. The code is mine now, and mine alone. So too are the relationships I cultivate. They're not just disguises anymore. I need them, even if they make me vulnerable. My father might not approve, but I'm no longer his disciple. I'm a master now, an idea transcended into life. And so this is my new path, which is a lot like the old one, only mine. To stay on that path, I need to work harder, explore new rituals, evolve. Am I evil? Am I good? I'm done asking those questions. I don't have the answers. Does anyone? ("Dexter", Season 2 Episode 11

Kutipan tersebut menunjukkan bahwa nilai moral yang diyakini Dexter bukanlah nilai-nilai moral yang berasal dari keyakinan agama. Hal ini juga dapat dilihat dalam contoh-contoh berikut. Dexter mengatakan: "Christmas is a time of expectations. If you're good, a red suited fat man will beak into your house and leave you presents. But Santa Claus doesn't exist. The most wonderful time of the year celebrates a lie." ("Dexter", Season 7 Episode 4) atau "No church bells. No Hallelujah chorus. Nothing feels different. If anything. I'm emptier ("Dexter", Season 5, Episode 3). Ketika dia dianjurkan untuk membuat pengakuan dosa karena pengakuan dosa akan meringankan jiwanya, Dexter menjawab "All the more proof I have no soul" ("Dexter", Season 4 Episode 7)

Jadi kekuatan pendorong perilaku berasal dari dirinya bukan dari kekuatan di luar dirinya, seperti kekuatan Tuhan. Pembuat seri ini terlihat menerapkan filsafat moral utilitarianisme sebagai penggerak Dexter. Filsafat moral utilitarianisme merupakan pemikiran Bentham yang dikenal dengan "the greatest happiness principle". Nilai filsafat moral ini pada dasarnya mengacu pada pemikiran bahwa apa yang dikatakan moral adalah ketika suatu tindakan dapat menyebabkan kebahagiaan bagi orang banyak, "... what is 
morally obligatory is that which produces the greatest amount of happiness for the greatest number of people," (Sweet, 2008). Menurut Sadler (2012) filsafat moral ini berpijak pada pemikiran kalkulus hedonis yaitu bahwa tindakan yang dapat dikatakan bermoral apabila dilihat dari empat faktor, yaitu (1) intensitas, atau seberapa tinggi kesenangan dan penderitaan yang diakibatkan dari tindakan tersebut, (2) berapa lama akibat yang timbul dari perbuatan tersebut, (3) kepastian atau seberapa besar adanya kepastian terjadinya dampak yang ditimbulkan atas suatu tindakan, dan (4) seberapa dekat akibat itu terjadi.

Faktor penting lain adalah seberapa banyak orang yang akan menerima dampak tersebut. Filsafat moral inilah yang dapat memberikan pembenaran apa yang dilakukan oleh Dexter. Meskipun Dexter telah membunuh lebih dari seratus orang, dia dapat menyelamatkan lebih banyak orang dengan tindakan pembunuhan tersebut karena yang dibunuhnya adalah pembunuh. Dengan fakta bahwa film ini populer dapat disimpulkan bahwa nilai moral ini dapat diterima oleh penonton. Pijakan yang rasional ini digunakan oleh pembuat film serial TV untuk merasionalisasi tindakan Dexter.

Pembenaran terhadap nilai-nilai moral Dexter dilakukan dengan menempatkan Dexter sebagai tokoh yang teralienasi dari masyarakat. Kehidupan digambarkan sebagai tempat gersang yang tidak bernilai. Hal ini terlihat dalam kutipan berikut.

Life is good. I'm not at all unhappy - I'm quite content to go about my life believing in nothing, with no fear that there might be something more out there... But I also have a son, and I also have to think about what he wants, and what's best for him, because who knows? Maybe he'll grow up to be someone who wants to think about... those kinds of things. ("Dexter", Season 6 Episode 1)
Kehidupan dirasakan Dexter sebagai kegelapan dan kekosongan yang berlangsung selama bertahun-tahun "I've lived in darkness a long time. Over the years, my eyes adjusted until the dark became my world and I could see". ("Dexter", Season 1 Episode 12); "I'm empty... but I found a way to make it feel less bottomless" ("Dexter", Season 1Episode 5) dan; "I always prided myself on being an outsider... but now... I feel the need to connect with someone" ("Dexter", Season 1 Episode1).

Karena kehidupan hanya dipenuhi dengan kegelapan dan kekosongan, Dexter menawarkan tiga pandangan sebagai cara hidup yaitu: pertama dengan berpura-pura dan kedua, melakukan sesuatu yang berguna untuk masyarakat seperti yang dikatakannya "Pretend. You pretend the feelings are there, for the world and for the people around you. Who knows, maybe one day they will be ("Dexter", Season 1 Episode 2). Dalam episode yang lain Dexter mengatakan: "I love Halloween ... people think its fun to pretend you're a monster. Me, I specd my life pretending I am not" ("Dexter", Season 1 Episode 4) dan "there is no secrets in life; just hidden truths that lie beneath the surface" ("Dexter", Season 1 Episode 2). Pandangan hidup kedua, yaitu melakukan sesuatu yang berguna untuk masyarakat banyak tanpa mempedulikan aturan atau tatanan yang ada karena aturan tersebut tidak dapat menyelesaikan masalah yang ada, membuat Dexter menjadi seorang pembunuh seperti yang dikatakannya: "I should know better than to count on the future. All you can ever believe in is now - this moment-because in a blink everything can change" ("Dexter", Season 7 Episode 1).

Moral berasal dari aturan-aturan agama dan etika yang berlaku dalam budaya tertentu. Aturan-aturan moral inilah membawa manusia pada kehidupan yang lebih baik, sedangkan Dexter ditempatkan di pihak yang beroposisi dengan aturan-aturan tersebut. Kalau pikiran 
manusia yang didorong oleh pikiran keduniawian membuat dapat merasionalisasikan apa yang ada di film karena kedekatan antara pikiran dan perasaan, Dexter dapat dikatakan sebagai simbol alienasi dan dehumanisasi. Karena itulah Dexter harus ditempatkan sebagai objek dalam masyarakat dan bukan subjek. Dia adalah korban dari masyarakat yang tidak bermoral. Konstruksi inilah yang dibawa oleh "Dexter" dan konstruksi inilah rupanya yang diharapkan oleh penonton seperti argumentasi berikut: "Perceivers form judgements, construct expectations, store information, and engage in a host of other perceptual and cognitive tasks - moreover, we have noted, they are biologically pre-wired to do so. ... spectators' responses are typically aroused somehow, and this arousal is provided by various kinds of stimuli situated throughout the text" (Rushton and Bettinson, 2010:159).

Proses menonton film adalah aktivitas yang berorientasi pada tujuan. Dengan kata lain, penonton terlebih dulu sudah tahu tujuan apa yang dia inginkan. Penonton bahkan telah "tuned" sebelum film mulai (Bordwell, 2007). Kesenangan pada tontonan seperti "Dexter" tentunya berasal dari suatu nilai moral yang dibenarkan oleh penonton atau berasal karena kekecewaan masyarakat terhadap apa yang terjadi di masyarakat. Kekecewaan terhadap kehidupan inilah yang menjawab mengapa "Dexter" populer. Menurut Frampton: "Since its invention, film has been compared to the mind, whether through analogy with human perception, dreams or the subconscious" (2008:15). Tokoh protagonis Dexter hadir sebagai pemenuhan harapan membawa keluar dari kekecewaan tersebut. Dia merupakan manifestasi "through the instinctual life of the body, its revulsions, impasses, and attractions, as well as through ideational content and spiritual inclinations" (McNeely, 2008: 212).

Standar moral tidaklah dapat bersifat absolut. Dalam karya sastra, setiap pembuat karya tersebut akan menciptakan dunia yang disertai nilai-nilai moral di dalamnya. Ketika manusia berkembang standar nilai inipun berkembang tergantung pada kebutuhan pada waktu dan tempat tertentu. Jadi nilai moral ini tentunya hasil dari suatu anggapan bahwa nilai moral tersebut sesuai dengan nilai yang dipercayai oleh masyarakat. Ketika kekecewaan terhadap realitas yang ada itu terjadi, masyarakat akan mencari pelarian itu dengan tontonan seperti "Dexter". Rushton dan Bettinson (2010: 36) menjelaskan teori Baudry dan Metz, yang dipengaruhi oleh konsep Lacan "mirror stage", bahwa film memberikan pemenuhan atas "lack" dalam masyarakat. Atau dengan kata lain, "Fiksi populer menciptakan mimpi bagi pembaca atau penonton dan mimpi ini merupakan pemenuhan simbolis dari harapan penonton atau pembaca" (Adi, 2011: 274). Dari pemikiran tersebut dapat diargumentasikan bahwa "Dexter" menjadi pelarian dari keadaan yang tidak dapat ditanggulangi dalam sistem nilai moral yang ada. "Dexter" dapat dikatakan sebagai penanda kekurangan atau "lack" yang terjadi di masyarakat meskipun sekaligus juga sebagai penanda kesenangan.

\section{SIMPULAN}

Berdasarkan hasil penelitian dan pembahasan dapat dikemukakan beberapa kesimpulan sebagai berikut. Pertama, penokohan Dexter berubah dari mainstream, yaitu bahwa Dexter adalah seorang pembunuh berantai yang telah membunuh lebih dari seratus orang. Perubahan tersebut menunjukkan adanya anakronisme. Meskipun perilaku Dexter mempunyai ciri-ciri seperti halnya antagonis yang melakukan pembunuhan karena gangguan mental, Dexter tidak mempunyai kriteria sebagai seorang antagonis melainkan protagonist. Meskipun terjadi anakronisme, penokohan pada Dexter dapat dipahami, diterima, dan dimaklumi oleh masyarakat. Penerimaan 
ini dibangun dari 3 tiga faktor penting, yaitu: (1) dibukanya celah kemanusiaan, (2) penguatan faktor thriller, dan (3) pengakomodasian intelektualitas manusia.

Bangunan tersebut terjadi karena berkembangnya tingkat kepuasan penonton dan meningkatnya intelektualitas masyarakat. Berkembangnya intelektualitas manusia menjadi faktor penting untuk membuat penonton menerima Dexter sebagai superhero, meskipun dia seorang pembunuh berantai. Kesimpulan ini terlihat dari kemunculan fenomena peningkatan cerita bergenre horor, kriminal, thriller, dan fantasi yang semakin rumit di televisi. Hal ini menunjukkan masyarakat sekarang semakin membutuhkan tontonan yang menantang dan semakin membutuhkan kecerdasan dalam memahami apa yang ditontonnya. Hal ini juga dapat menjawab mengapa "Dexter" begitu dipuja masyarakat dan sekaligus juga menjawab mengapa terjadi anakronisme melalui penciptaan "Dexter"

Kedua, bahwa hero menegakkan hukumnya sendiri baik secara legal maupun ilegal menunjukkan semakin diterimanya filsafat moral yang berpijak pada pemikiran kalkulus hedonis. Filsafat moral inilah yang dapat memberikan pembenaran apa yang dilakukan oleh Dexter. Meskipun Dexter telah membunuh lebih dari seratus orang, dia dapat menyelamatkan lebih banyak orang karena orang-orang yang dibunuhnya adalah pembunuh. Pijakan yang rasional dalam filsafat moral ini digunakan oleh pembuat film serial TV untuk merasionalisasi tindakan Dexter. Pembenaran terhadap nilai-nilai moral Dexter dilakukan dengan menempatkan Dexter sebagai tokoh yang teralienasi dari masyarakat. Dexter seakan menjadi pelarian dari keadaan yang tidak dapat ditanggulangi dalam sistem nilai moral yang ada.

\section{UCAPAN TERIMA KASIH}

Tulisan ini diringkas dengan beberapa perubahan dari penelitian yang dilakukan tahun 2012 dengan judul "Anachronism in Popular Literature: A Study of Television Series "Dexter". U.S. Bureau of Statistics. Akhirnya, kami ingin menyampaikan ucapan terima kasih kepada berbagai pihak yang telah memungkinkan terselenggaranya penelitian ini. Ucapan terima kasih, pertama-tama, disampaikan kepada ketua Jurusan Sastra Inggris, Fakultas Ilmu Budaya Universitas Gadjah Mada yang memfasilitasi penelitian ini. Kedua, ucapan terima kasih disampaikan kepada asisten peneliti Rahmawan Jatmiko, S.S., M.A. yang telah banyak membantu dalam penelitian ini. Terima kasih ditujukan kepada Prof. Dr. Suminto A. Sayuti dan Dr. Wiyatmi M.Hum. sebagai reviewer yang telah memberi masukan, catatan penting, dan pembenahan aspek kebahasaan untuk penyempurnaan artikel ini.

\section{DAFTAR PUSTAKA}

Adi, I. R. 2008. Mitos Dibalik Film Laga Amerika. Yogyakarta: Gadjah Mada University Press.

Adi, I. R. 2011. Fiksi Populer: Teori dan Metode Kajian. Yogyakarta: Pustaka Pelajar.

Altman, R. 1986. "A Semantic/Syntactic Approach to Film Genre" Cinema Journal, 23/3: 6-18 dalam Grant, Barry K. (ed.). Film Genre Reader. Austin Texas: University of Texas Press. Hlm. 6-18

Bordwell, D. (2007) This is your brain on movies, maybe (March 7). Online at: http://www.davidbordwell.net/ blog/?p=300

Caute, D. 1972. The Illusion, New York: Harper \& Row.

Dexter: Season 1-7 Box Set. Weaki TV. Rakuten.co.id

Frampton, D. 2008. Filmosophy. London: Wallflower Press.

Good, R. 2010. Dexter: Why Ordinary People Love a Brutal Murderer. http://technora- 
ti.com/entertainment/celebrity/article/ dexter-why-ordinary-people-love-a/ (Diunduh 13/06/2012)

Hoggart, R. 1973. Speaking to Each Other: Volume 2: About Literature. Harmondsworth: Penguin.

IMDb "The Most Popular TV Series", 2013. http://www.imdb.com/search/ title?t itle_type $=t v \_s e r i e s$ (Diunduh 02/06/13)

IMDb, 2013.http://www.imdb.com/search/ title?num_votes $=5000$,\&sort=user_rating, desc\&title_type $=t v \_s e r i e s$ (Diunduh, 2/1/13)

Jinks, W. 1974. The Celluloid Literature Film in the Humanities. Beverly Hills: Glencoe Press.

Johnson, JG, Cohen P, Smailes EM, Kasen S, Brook JS. 2002. "Television viewing and aggressive behavior during adolescence and adulthood.http:// nlm. nih.gov/pubmed/11923542

Kondology, A. 2013. Ray Donovan Delivers Showtime's Highest-Rated Original Series Premiere Ever + "Dexter" Premiere Viewership Records vbythenumbers. zap2it.com/2013/07/01/ray-donovandelivers-showtimes-highest-ratedoriginal-series-premiere-ever-with-304-million-viewers/189861/ (diunduh 04/07/2013)

Linberg, A. M. 1979. "The Changing Concept of Heroes" Minnesota History, Winter pp.306-2011. Minnesota Historical Society. http:// collections. mnhs.org/MNHistoryMagazine/ articles/46/v46i08p306-311.pdf (Diunduh 23/11/12)

McNeely, D. A. 2008. "An archetypal approach." ( Polly Young-Eisendrath (ed). The Cambridge Companion to Jung. Cambridge, NewYork: Cambridge University Press. Pp 211-232.

Michaud, N. 2011. “Can We Blame a Man with No Choice?" George A Reisch (ed) Popular Culture and Philosophy vol.
58.Chicago, Illinois: Carus Publishing Company. Hlm. 36-43.

Muir, J. K. 2011. “The Killing Joke". George A Reisch (ed) Popular Culture and Philosophy vol. 58. Chicago, Illinois: Carus Publishing Company. Pp 3-13

Reisch, G. A. 2011 "Know Thyself?" in George A Reisch (ed) Popular Culture and Philosophy vol. 58.Chicago, Illinois: Carus Publishing Company. Pp xi-xiv

Rushton, R. \& Garry B. 2010. What is Film Theory?: An Introduction to Contemporary Debates. Bershire, England: McGraw-Hill

Sadler, G. B. 2012. "Philosophy Core Concept: Bentham, The Hedonic Calculus" http://www.youtube.com/ watch?v=5MAygHXUwtk (Diunduh: $1 / 12 / 12$ )

Scholasticus, K. 2012. Anachronism Examples in Literature http://www.buzzle. com/ articles/anachronism-examplesin-literature.html (Diunduh 13/4/13)

Sherman, J. 2009 "Gangstas R Us: Why we love crime drama", Ambigamy. http:// www.psychologytoday.com/blog/ ambigamy/200903/gangstas-r-uswhy-we-love-crime-drama. (Diunduh $2 / 8 / 12$ )

Sumarjo, J and Saini K.M. 1988. Apresiasi Kesusastraan. Jakarta: P.T. Gramedia

Sweet, W. 2008. "Jeremy Bentham (17481832)" http://www.iep.utm.edu/ bentham/ (Diunduh 18/4/12)

The Most Popular Television Series http://www.imdb.com/search/ title?num_votes $=5000, \&$ sort $=$ user rating,desc\&title_type $=t v \_s e r i e s$

Waller, S. 2010. Serial Killers. New Jersey: Willey Blacwell

William, R. 1998. "The Analysis of Culture", Storey, John ed. Cultural Theory and Popular Culture. London, Prentice Hall. 